\title{
Compostagem e vermicompostagem de dejetos líquidos de bovinos leiteiros e cama aviária
}

\author{
Valente, B.S. ${ }^{@}$; Xavier, E.G. '; Lopes, M. ${ }^{2}$; Pereira, H. da S. ${ }^{1}$ e Roll, V.F.B. ${ }^{1}$
}

'Departamento de Zootecnia. Faculdade de Agronomia Eliseu Maciel. Universidade Federal de Pelotas. Pelotas. RS. Brasil. ${ }^{2}$ Faculdade de Agronomia Eliseu Maciel da Universidade Federal de Pelotas. Pelotas. RS. Brasil.

\section{PALAVRAS CHAVE ADICIONAIS}

Avicultura.

Meio ambiente.

Produç̃o animal.

Compostagem.

\section{RESUMO}

O confinamento de animais proporciona uma maior produção de resíduos orgânicos, - que acaba causando mudanças físicas, químicas e biológicas no meio ambiente, quando disposto no solo sem um tratamento adequado. Tecnologias como a compostagem e a vermicompostagem podem ser medidas mitigadoras do impacto ambiental causados pela produção em confinamento. Objetivou-se avaliar a compostagem, a vermicompostagem e a combinação entre os dois processos no tratamento da mistura de dejetos líquidos de bovinos leiteiros e cama aviária. Na compostagem pelo método aeração passiva foi utilizada uma estrutura nas dimensões de $12 \mathrm{~m}$ de comprimento, $2 \mathrm{~m}$ de largura e 1,80 m de altura, coberta com filme de polietileno de baixa densidade e aberta nas laterais, que comportou três caixas de plástico reforçado com fibra de vidro. A compostagem pelo método aeração ativa caracterizou-se pela formação de pilha e por revolvimentos intermitentes. Na vermicompostagem foram utilizados 12 caixas de madeira, que receberam 200 minhocas da espécie Eisenia fetida. Conclui-se que a compostagem pelos métodos aeração passiva e ativa não é eficiente para promover a estabilização da mistura de dejetos líquidos de bovinos leiteiros e cama aviária. O processo de vermicompostagem promove a bioestabilização da mistura de dejetos líquidos de bovinos leiteiros e cama aviária em um período de 60 dias.

\section{Composting and vermicomposting of dairy cattle residues and poultry bed}

\section{SUMMARY}

Animal confinement provides a higher production of organic residues that causes physical, chemical and biological changes in the environment if disposed in the soil without an adequate treatment. Technologies such as composting and vermicomposting might mitigate the environmental impact of animal production in confinement. The objective of this study was to evaluate composting, vermicomposting and its combination for the treatment of a mixture of bovine liquid waste and poultry litter. For the passive composting aeration method a 12 $\mathrm{m}$ length, $2 \mathrm{~m}$ width, and $1.80 \mathrm{~m}$ height structure was utilized, covered with a low density polyethylene film and side opened. Such structure sheltered three plastic-fiberglass reinforced boxes. The active composting aeration method was characterized by a pile formation and intermittent revolving. For the vermicomposting, a total of 12 wooden boxes containing 200 earthworms (Eisenia fetida) were utilized. In conclusion, neither passive aeration nor active aeration composting is efficient for promoting the stabilization of a mixture of bovine liquid waste and poultry litter. The vermicomposting process promotes the biostabilization of a mixture of bovine liquid waste and poultry litter in a period of 60 days.

\section{INFORMACIÓN}

\section{Cronología del artículo.}

Recibido/Received: 14.01.2015

Aceptado/Accepted: 18.01.2016

On-line: 16.03.2016

Correspondencia a los autores/Contact e-mail:

bsvalente@terra.com.br

\section{INTRODUÇÃO}

O confinamento de animais surgiu como uma alternativa para a alta demanda de alimentos, permitindo assim uma maior produção em pequena área. Entretanto, sistemas com alta densidade animal causam problemas ambientais devido ao aumento da produção de resíduos, pois sua taxa de geração é maior do que a de degradação, o que acaba acarretando mudanças físicas, químicas e biológicas no meio ambiente, quando disposto na forma in natura. Tecnologias apropriadas de gerenciamento associadas à superprodução de resíduos orgânicos animais podem mitigar os riscos ambientais através da sua estabilização prévia para posterior uso ou disposição no solo como fertilizante orgânico. 
A compostagem é normalmente utilizada em resíduos sólidos provenientes das mais diversas fontes orgânicas. No entanto, os resíduos líquidos também podem ser passíveis dessa tecnologia, sendo que para isso há necessidade de alterar suas características físicas, através de agentes de estruturação, como cama de aviário, casca de arroz, serragem e maravalha. $\mathrm{O}$ sistema apresenta características e processos similares independentemente do método de compostagem utilizado, caracterizando-se por uma sucessão de diferentes populações de micro-organismos aeróbios que colonizam a biomassa, produzindo calor e desprendimento de $\mathrm{CO}_{2}$ (Liu et al., 2011). Temperaturas altas e liberação de $\mathrm{CO}_{2}$ estão relacionadas ao metabolismo exotérmico e à respiração dos micro-organismos que colonizaram a massa em compostagem e que são responsáveis pela maior parte das modificações físico-químicas na biomassa, determinando assim a fase em que se encontra a compostagem (Bernal et al., 2009).

Nesse sentido, a vermicompostagem é uma alternativa à compostagem tradicional por ser um processo aeróbio que envolve a fragmentação e a digestão parcial de resíduos orgânicos pelas minhocas, conjuntamente com a sua microflora intestinal, bem como micro-organismos mesófilos presentes na matéria orgânica (Vig et al., 2011). Fornes et al. (2012) ressaltam que a fragmentação dos substratos aumenta a área de exposição aos micro-organismos, propiciando a aceleração do processo de vermicompostagem.

Outro aspecto importante é a combinação entre a compostagem e a vermicompostagem a fim de otimizar a reciclagem de resíduos (Yadav et al., 2012). Fornes et al. (2012) ressaltam que o propósito de combinar os dois sistemas baseia-se na premissa de que a compostagem tem a capacidade de sanitização e eliminação de componentes tóxicos, enquanto que a vermicompostagem reduz rapidamente o tamanho das partículas dos substratos, aumentando os nutrientes disponíveis, produzindo um adubo mais rico em nitrogênio, fósforo e potássio. Além disso, a combinação das duas tecnologias reduz o tempo para obtenção do adubo orgânico. Ndegwa e Thompson (2001) compararam materiais idênticos obtidos a partir da vermicompostagem e duas combinações de tecnologias: vermicompostagem sucedido por compostagem e compostagem seguido pela vermicompostagem. Os resultados mostraram que a compostagem seguida pela vermicompostagem foi mais efetiva na estabilização de esterco bovino, acarretando menor impacto ambiental.

Neste contexto, objetivou-se avaliar a compostagem, a vermicompostagem e a combinação entre os dois processos no tratamento da mistura de dejetos líquidos de bovinos leiteiros e cama aviária.

\section{MATERIAL E MÉTODOS}

O experimento foi realizado entre outubro de 2008 e janeiro de 2009, nos Setores de Compostagem e de Vermicompostagem do Laboratório de Ensino e Experimentação Zootécnica (LEEZO) Professor Doutor Renato Rodrigues Peixoto do Departamento de Zootecnia (DZ) da Faculdade de Agronomia Eliseu Maciel
(FAEM), da Universidade Federal de Pelotas (UFPEL), localizado no município de Capão do Leão/RS.

Utilizaram-se dejetos líquidos de bovinos leiteiros e cama aviária como substratos. Os dejetos líquidos de bovinos leiteiros em lactação da raça Jersey foram cedidos pela Embrapa Terras Baixas, localizada no município de Capão do Leão/RS. A cama aviária de maravalha de pinus (Pinus spp.), de dois lotes de 35 dias de frangos de corte, que recebeu sulfato de cálcio $\left(\mathrm{CaSO}_{4}\right)$ para a sua desinfecção, foi obtida junto ao LEEZO.

Foram avaliadas três tecnologias na mistura de dejetos líquidos de bovinos leiteiros e cama aviária.

\section{Compostagem PElO MÉtOdo AERAÇÃo PASSIVA (COM PASSIVA)}

$\mathrm{Na}$ compostagem pelo método aeração passiva foi utilizada uma estrutura nas dimensões de $12 \mathrm{~m}$ de comprimento, $2 \mathrm{~m}$ de largura e 1,80 m de altura, coberta com filme de polietileno de baixa densidade (PEBD) de $150 \mu \mathrm{m}$ de espessura e aberta nas laterais, que comportou três caixas de plástico reforçado com fibra de vidro, com capacidade de 1000 L cada uma, nas dimensões de $1,13 \mathrm{~m}$ de base, 0,93 $\mathrm{m}$ de altura e 1,32 $\mathrm{m}$ de diâmetro. Esta estrutura teve a finalidade de proteger os substratos contra as chuvas que pudessem ocorrer durante o período experimental e proporcionar maior penetração dos raios solares, favorecendo a evaporação do excedente de água e promovendo a compostagem da mistura dos resíduos orgânicos.

$\mathrm{O}$ procedimento adotado na montagem do experimento foi baseado no volume dos substratos, sendo utilizado um recipiente graduado com capacidade de 12 L. Na primeira caixa, colocou-se a cama aviária anotando-se o número de recipientes necessários para atingir a altura de 0,70 m. A quantidade de recipientes foi multiplicada pela sua capacidade de volume, obtendo-se assim o volume total de cama aviária no interior da caixa, que foi de 864 L. Deste volume, retirou-se 240 L de cama aviária para cada uma das outras duas caixas, formando assim as primeiras camadas, nas duas repetições restantes. $\mathrm{O}$ volume de dejeto líquidos de bovinos a ser adicionado por caixa foi calculado através de regra de três simples, tomando-se como base a taxa de aplicação de 2 L de dejetos líquidos para cada 3 L de cama aviária, obtendo-se assim o volume total de $576 \mathrm{~L}$ a ser aplicado por caixa. Os dejetos líquidos foram previamente homogeneizados antes de cada aplicação. Foi utilizada a taxa de incorporação de 40 , 30, 20 e 10\%, conforme metodologia descrita por Dai Prá (2006), em intervalos de 10 dias entre as aplicações.

A tubulação de PVC, com diâmetro de $75 \mathrm{~mm}$ e altura de $0,85 \mathrm{~m}$, foi colocada verticalmente nas três caixas para permitir a aeração passiva da massa em compostagem. Os cinco canos, perfurados em toda a sua extensão, foram dispostos a $0,20 \mathrm{~m}$ da borda da caixa e a uma distância de $0,30 \mathrm{~m}$ entre si. Somente após a montagem e instalação dos tubos, procedeu-se a impregnação com dejetos líquidos de bovinos leiteiros até a altura de 0,70 m.

Na primeira aplicação, o volume de 230,4 L de dejetos líquidos de bovinos foi absorvido por camada de 
Tabela I. Composição química dos substratos cama aviária e dejetos líquidos de bovinos leiteiros, antes de cada impregnação (Chemical composition of substrates of poultry litter and liquid residues of dairy cattle before each impregnation).

\begin{tabular}{|c|c|c|c|c|c|c|c|c|}
\hline & \multirow{3}{*}{ Cama aviária } & \multicolumn{7}{|c|}{ Dejetos líquidos de bovinos leiteiros antes de cada impregnação } \\
\hline & & 0 & 10 & 20 & 30 & 15 & 30 & 45 \\
\hline & & \multicolumn{7}{|c|}{ (dias) } \\
\hline $\mathrm{pH}$ & 9,7 & 6,8 & 6,6 & 6,1 & 6,7 & 6,8 & 7,5 & 7,8 \\
\hline UMID (\%) & 9,7 & 98,5 & 98,0 & 96,1 & 98,6 & 99,0 & 94,0 & 98,1 \\
\hline $\mathrm{MO}(\%)$ & 89,1 & 70,5 & 72,1 & 75,8 & 72,1 & 66,9 & 76,4 & 67,0 \\
\hline CZ (\%) & 10,9 & 29,5 & 27,9 & 24,3 & 27,9 & 33,1 & 23,7 & 33,0 \\
\hline $\mathrm{N}(\%)$ & 2,4 & 3,4 & 3,0 & 2,4 & 2,9 & 3,6 & 2,4 & 2,6 \\
\hline $\mathrm{C}(\%)$ & 49,5 & 39,2 & 40,1 & 42,1 & 40,1 & 37,2 & 42,4 & 37,2 \\
\hline $\mathrm{C} / \mathrm{N}$ & 20,9 & 11,5 & 13,5 & 17,5 & 13,7 & 10,4 & 17,9 & 14,6 \\
\hline$P\left(g_{k g}^{-1}\right)$ & 10,5 & 5,6 & 5,6 & 4,6 & 7,0 & 10,8 & 3,8 & 7,1 \\
\hline $\mathrm{K}\left(\mathrm{g} \mathrm{kg}^{-1}\right)$ & 17,5 & 24,6 & 19,7 & 16,6 & 35,1 & 47,4 & 12,8 & 48,3 \\
\hline $\mathrm{Ca}\left(\mathrm{g} \mathrm{kg}^{-1}\right)$ & 36,8 & 5,6 & 2,6 & 5,0 & 10,0 & 17,0 & 8,1 & 12,6 \\
\hline $\mathrm{Mg}\left(\mathrm{g} \mathrm{kg}^{-1}\right)$ & 6,9 & 5,1 & 4,6 & 1,7 & 2,9 & 9,8 & 4,0 & 7,8 \\
\hline
\end{tabular}

UMID= umidade; $M O=$ matéria orgânica total; $C Z=$ cinzas; $N=$ nitrogênio total; $C=$ carbono orgânico total; $C / N=$ relação carbono/nitrogênio; $\mathrm{P}=$ fósforo total; $\mathrm{K}=$ potássio total; $\mathrm{Ca}=$ cálcio total; $\mathrm{Mg}=$ magnésio total.

cama aviária. Nas demais impregnações, 30 (172,8 L), 20 (115,2 L) e 10\% (57,6 L), foram realizadas escarificações no material celulósico à medida que os dejetos líquidos de bovinos foram sendo adicionados.

Ao final dos 40 dias do processo, a biomassa foi homogeneizada, sendo uma parte transferida para a compostagem com aeração ativa e a outra para o processo de vermicompostagem.

\section{COMPOSTAGEM PELO MÉTOdO AERAÇÃO ATIVA (COM ATIVA)}

A compostagem pelo método aeração ativa foi realizada em um galpão com piso impermeabilizado com uma lona plástica e sem paredes laterais, sendo o local fechado somente por uma tela. Foi formada uma pilha da mistura de dejetos líquidos de bovinos leiteiros e cama aviária, nas dimensões de $3 \mathrm{~m}$ de comprimento, 1,60 m de largura e $1 \mathrm{~m}$ de altura. Estacas de madeira numeradas foram colocadas em cada ponto de coleta e de aferição, constituindo assim cinco repetições. No decorrer de 60 dias de compostagem foram realizados revolvimentos e adição de dejetos líquidos de bovinos leiteiros a cada 15 dias, a fim de manter a umidade da biomassa. Para isso, foi utilizada uma taxa de incorporação de $15 \%$, que foi multiplicada pelo volume total de dejetos impregnados no decorrer da compostagem com aeração passiva, o que correspondeu a 86,5 L.

\section{VERMICOMPOSTAGEM (VER)}

Na vermicompostagem, as 12 unidades experimentais constaram de caixas de madeira não aromáticas, nas dimensões de 0,50 m de comprimento, 0,40 $\mathrm{m}$ de largura e 0,30 m de altura, que foram alocadas em um galpão fechado. Foram inoculadas 200 minhocas adultas e cliteladas da espécie Eisenia fetida (Savigny, 1826), que permaneceram por 60 dias em cada caixa. $\mathrm{O}$ teor de umidade foi verificado a cada 15 dias, através do teste da mão conforme método de Cooper et al. (2010), em que o teor ótimo de água é determinado pela formação de uma massa firme, quando a biomassa é comprimida pelas mãos. Utilizou-se palha de gramí- nea seca como cobertura da biomassa a fim de evitar a perda de umidade.

As avaliações da temperatura da biomassa nos sistemas de compostagem foram realizadas em dois períodos do dia, às 9:00 e 16:00 h, utilizando-se um termômetro digital $\left( \pm 0,5^{\circ} \mathrm{C}\right.$ COTERM 180$)$ com haste de $0,17 \mathrm{~m}$.

No Laboratório de Nutrição Animal do DZ/FAEM/ UFPEL foi realizada a determinação da umidade, $\mathrm{pH}$ e nitrogênio total $(\mathrm{N})$, segundo metodologia descrita por Silva e Queiroz (2004), e também para a análise da matéria orgânica total (MO), teor de cinzas (CZ) e do carbono orgânico total (C), conforme metodologia descrita por Kiehl (1985). A relação C / $\mathrm{N}$ foi obtida pela equação $\mathrm{C} / \mathrm{N}=\% \mathrm{C} \div \% \mathrm{~N}$, em que $\% \mathrm{C}=$ porcentagem de carbono orgânico total na amostra; \%N= porcentagem de nitrogênio total na amostra, conforme descrito por Tedesco et al. (1995). No Laboratório de Química do Solo do Departamento de Solos da FAEM/UFPEL foram analisados os teores totais de fósforo $(\mathrm{P})$, magnésio $(\mathrm{Mg})$, cálcio $(\mathrm{Ca})$ e potássio $(\mathrm{K})$ a partir da metodologia descrita por Tedesco et al. (1995).

As análises da composição química foram realizadas em triplicata, sendo que a primeira amostragem correspondeu aos substratos iniciais cama aviária e dejetos líquidos de bovinos leiteiros antes de cada impregnação, conforme apresentado na tabela I. As demais coletas foram realizadas nos seguintes períodos: $0,10,20,30$ e 40 dias de compostagem pelo método aeração passiva; 0, 45 e 60 dias de compostagem pelo método aeração ativa, bem como a 0, 45 e 60 dias do processo de vermicompostagem, correspondendo respectivamente a T1, T2, T3, T4, T5, T6, T7, T8, T9, T10 e T11. As amostragens nos períodos zero referem-se à mistura dos substratos dejetos líquidos de bovinos leiteiros e cama aviária.

O delineamento adotado foi o inteiramente casualizado, com cinco e quatro repetições por tratamento para os processos de compostagem e de vermicom- 


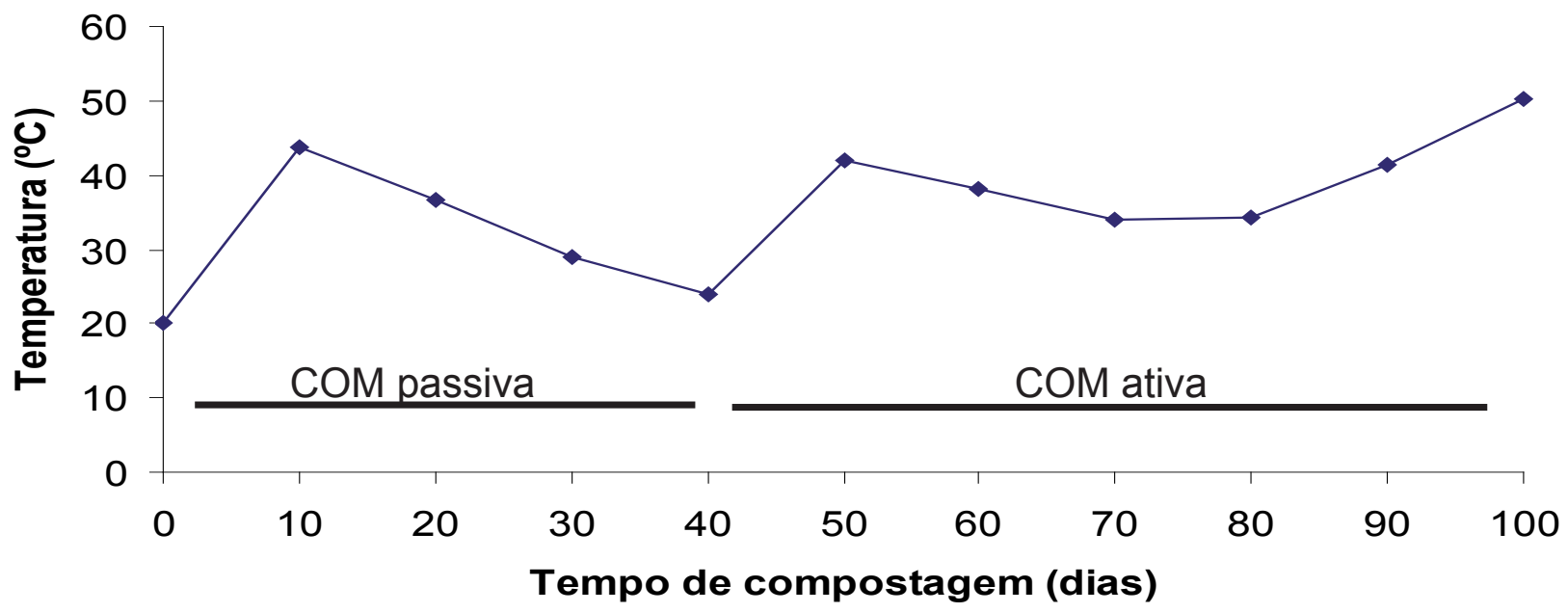

Figura 1. Médias da temperatura da biomassa durante os processos de COM passiva e COM ativa, da mistura de dejetos líquidos de bovinos leiteiros e cama aviária. COM passiva: compostagem aeração passiva (0-40 dias); COM ativa: compostagem aeração ativa (40-100 dias) (Biomass temperature means during the passive COM and active COM process of a mixture of liquid residues of dairy cattle and poultry litter. Passive COM: composting passive aeration (0-40 days); Active COM: composting active aeration (40-100 days)).

postagem, respectivamente. Os dados coletados foram submetidos à análise de variância (ANOVA) e ao procedimento LSMEANS do programa Statistical Analysis System versão 9.1 (SAS Institute Inc. 2002-2003) e regressão polinomial, sendo as médias comparadas pelo teste de Tukey a $5 \%$ de significância. Contrastes ortogonais foram utilizados para comparações entre as tecnologias de tratamento e os adubos orgânicos produzidos.

\section{RESULTADOS E DISCUSSÃO}

Na figura 1, pode ser observado no dia zero que a média da temperatura da biomassa, que foi submetida ao processo de compostagem pelo método aeração passiva (COM passiva), foi de $20,1^{\circ} \mathrm{C}$. A partir deste período, houve um aumento da temperatura atingindo $43,8^{\circ} \mathrm{C}$ aos 10 dias de compostagem, demonstrando intensa atividade biológica mesofílica na biomassa, devido à presença de condições favoráveis, como umidade, aeração, relação $\mathrm{C} / \mathrm{N}$, granulometria do material e dimensões das caixas (Valente et al., 2011). Bactérias, fungos e actinomicetos mesófilos, que são dominantes na fase inicial da compostagem, se alimentam de componentes da matéria orgânica facilmente disponível, como açúcares, aminoácidos, proteínas, ácidos nucleicos e lipídios (Bernal et al., 2009).

No entanto, verificou-se a partir deste período, que a temperatura da biomassa $\left(36,7^{\circ} \mathrm{C}\right)$ decresceu progressivamente, persistindo até os 40 dias $\left(24,1^{\circ} \mathrm{C}\right)$ da COM passiva, possivelmente devido ao resfriamento proporcionado pela impregnação dos dejetos líquidos de bovinos leiteiros a cama aviária (tabela I) e também pela diminuição da atividade microbiológica envolvida na estabilização da matéria orgânica. Da mesma forma, o intervalo de dez dias entre as impregnações associado ao maior teor de umidade dos dejetos no decorrer dos períodos, que variou de 96,1 a 98,6\%, pode ter colaborado para a morte gradativa de parte dos micro-organismos mesófilos ou para o seu estado de dormência. Corroborando com as afirmações, na tabela II, constatou-se que a partir dos 10 dias, o teor de umidade da biomassa manteve-se significativamente superior ao do período inicial (dia zero) da COM passiva, que foi de $65 \%(\mathrm{p}<0,05)$. Kader et al. (2007) explicam que o excesso de umidade reduz a penetração de oxigênio, pois as moléculas de água se aderem fortemente à superfície das partículas, saturando os seus micro e macroporos.

Por outro lado, a transferência de parte da biomassa para ser compostada pelo método pilha com aeração ativa (COM ativa), proporcionou uma elevação da temperatura $\left(41,8^{\circ} \mathrm{C}\right)$ no decorrer dos 50 dias de processo (figura 1). Estes resultados demonstram que a incorporação de oxigênio devido ao manejo da biomassa, favoreceu o crescimento e desenvolvimento de micro-organismos mesófilos que estavam possivelmente em estágio de dormência na massa em compostagem. Entretanto, podem ser observados nos períodos subsequentes, decréscimos na temperatura até os 80 dias de compostagem $\left(34,5^{\circ} \mathrm{C}\right)$, indicando que a impregnação de 86,5 L de dejetos líquidos a cada 15 dias à cama aviária, associado ao seu alto teor de umidade, que variou de 94 a $99 \%$, prejudicou a atividade microbiana no meio. Inácio e Miller (2009) explicam que em níveis de umidade acima de $65 \%$, a água promove um deslocamento do ar, presente nos espaços porosos da matriz da pilha, reduzindo a continuidade entre os poros, limitando assim a difusão do ar e, consequentemente, propiciando condições para a atividade microbiana anaeróbia. Resultados semelhantes foram encontrados por Barrington et al. (2003), os quais avaliaram o efeito da aeração passiva e ativa na compostagem de dejetos de suínos com três substratos diferentes (maravalha, palha e feno), verificando que a umidade de $65 \%$ no substrato maravalha influenciou no aumento da temperatura apenas entre o segundo e sexto dias.

Diferentemente, o aumento da temperatura da biomassa aos $90\left(41,3^{\circ} \mathrm{C}\right)$ e 100 dias $\left(50,2^{\circ} \mathrm{C}\right)$ do processo (figura 1), possivelmente tenha ocorrido devido 
Tabela II. Composição química da mistura de dejetos líquidos de bovinos leiteiros e cama aviária submetidos a diferentes tempos de compostagem aeração passiva (COM passiva) e ativa (COM ativa) e de vermicompostagem (VER) (Chemical composition of a mixture of liquid residues of dairy cattle and poultry litter subjected to different periods of composting passive aeration (passive COM), composting active aeration (active COM) and vermicomposting (VER)).

\begin{tabular}{|c|c|c|c|c|c|c|c|c|c|c|c|}
\hline & UMID & $\mathrm{CZ}$ & $\mathrm{N}$ & $\mathrm{MO}$ & $\mathrm{C}$ & \multirow{2}{*}{$\mathrm{pH}$} & \multirow{2}{*}{$\mathrm{C} / \mathrm{N}$} & $\mathrm{P}$ & $\mathrm{K}$ & $\mathrm{Ca}$ & $\mathrm{Mg}$ \\
\hline & & & $\%$ & & & & & \multicolumn{4}{|c|}{$\mathrm{g} \mathrm{kg}^{-1}$} \\
\hline \multicolumn{12}{|c|}{ COM passiva } \\
\hline $\mathrm{T} 1(0)$ & $65,0^{\mathrm{B}}$ & $15,0^{C}$ & 1,3 & $85,0^{A}$ & $47,2^{\mathrm{A}}$ & $9,0^{A}$ & 36,0 & $6,0^{\mathrm{B}}$ & $15,0^{\mathrm{A}}$ & $19,5^{\mathrm{B}}$ & $5,1^{\mathrm{B}}$ \\
\hline T2 (10) & $77,3^{\mathrm{A}}$ & $20,5^{\mathrm{B}}$ & 1,5 & $79,5^{\mathrm{B}}$ & $44,2^{\mathrm{B}}$ & $8,5^{\mathrm{B}}$ & 30,3 & $7,5^{\mathrm{AB}}$ & $8,1^{\mathrm{B}}$ & $35,2^{A B}$ & $5,9^{A B}$ \\
\hline T3 (20) & $75,8^{\mathrm{A}}$ & $23,6^{A B}$ & 1,4 & $76,4^{\mathrm{BC}}$ & $42,4^{\mathrm{BC}}$ & $7,7^{\mathrm{C}}$ & 31,1 & $6,8^{A B}$ & $6,0^{\mathrm{B}}$ & $30,9^{A B}$ & $6,3^{\mathrm{AB}}$ \\
\hline T4 (30) & $76,2^{\mathrm{A}}$ & $24,3^{\mathrm{A}}$ & 1,4 & $75,7^{c}$ & $42,0^{C}$ & $8,2^{\mathrm{BC}}$ & 30,0 & $9,1^{\mathrm{A}}$ & $8,9^{\mathrm{B}}$ & $36,9^{A B}$ & $7,2^{\mathrm{A}}$ \\
\hline T5 (40) & $75,0^{\mathrm{A}}$ & $23,9^{A B}$ & 1,3 & $76,1^{\mathrm{BC}}$ & $42,3^{\mathrm{BC}}$ & $8,5^{\mathrm{B}}$ & 33,3 & $8,4^{A B}$ & $10,1^{A B}$ & $42,6^{\mathrm{A}}$ & $6,3^{\mathrm{AB}}$ \\
\hline \multicolumn{12}{|c|}{ COM ativa } \\
\hline T6 (0) & $69,8^{\mathrm{A}}$ & $21,6^{B}$ & $1,4^{\mathrm{B}}$ & $78,4^{\mathrm{A}}$ & $43,5^{\mathrm{A}}$ & $8,7^{\mathrm{B}}$ & $31,8^{A}$ & 10,6 & $17,3^{\mathrm{B}}$ & $30,9^{A}$ & 8,8 \\
\hline T7 (45) & $68,1^{\mathrm{A}}$ & $24,1^{\mathrm{AB}}$ & $1,4^{\mathrm{B}}$ & $75,9^{\mathrm{AB}}$ & $42,2^{\mathrm{AB}}$ & $8,3^{c}$ & $30,8^{\mathrm{A}}$ & 10,9 & $25,2^{\mathrm{A}}$ & $28,9^{A}$ & 8,3 \\
\hline T8 (60) & $63,1^{\mathrm{B}}$ & $26,4^{\mathrm{A}}$ & $1,7^{\mathrm{A}}$ & $73,6^{\mathrm{B}}$ & $40,9^{\mathrm{B}}$ & $9,0^{A}$ & $24,7^{\mathrm{B}}$ & 11,1 & $19,5^{\mathrm{B}}$ & $30,1^{\mathrm{A}}$ & 8,3 \\
\hline \multicolumn{12}{|l|}{ VER } \\
\hline T9 (0) & $76,9^{A}$ & $22,5^{\mathrm{B}}$ & $1,4^{\mathrm{C}}$ & $77,5^{\mathrm{A}}$ & $43,1^{\mathrm{A}}$ & 8,7 & $31,5^{\mathrm{A}}$ & $9,0^{\mathrm{B}}$ & $14,0^{\mathrm{B}}$ & 39,5 & 8,5 \\
\hline T10 (45) & $68,1^{\mathrm{B}}$ & $33,5^{\mathrm{A}}$ & $1,5^{\mathrm{B}}$ & $66,5^{\mathrm{B}}$ & $36,9^{\mathrm{B}}$ & 9,0 & $24,2^{\mathrm{B}}$ & $7,8^{\mathrm{B}}$ & $14,1^{\mathrm{B}}$ & 38,4 & 8,8 \\
\hline $\mathrm{T} 11(60)$ & $66,0^{\mathrm{B}}$ & $30,7^{\mathrm{A}}$ & $1,9^{A}$ & $69,3^{\mathrm{B}}$ & $38,5^{\text {B }}$ & 9,1 & $20,4^{\mathrm{C}}$ & $14,8^{\mathrm{A}}$ & $19,4^{\mathrm{A}}$ & 36,5 & 9,9 \\
\hline
\end{tabular}

Médias seguidas de letras maiúsculas diferentes, na mesma coluna, diferem entre si pelo teste de Tukey a $5 \%$. UMID= umidade; MO= matéria orgânica total; $C Z=$ cinzas; $N=$ nitrogênio total; $C=$ carbono orgânico total; $C / N=$ relação carbono/nitrogênio; $P=$ fósforo total; $K=$ potássio total; $\mathrm{Ca}=$ cálcio total; $\mathrm{Mg}=$ magnésio total.

à redução significativa do teor de umidade da biomassa aos 60 dias $(63,1 \%)$ da COM ativa (tabela II), o que favoreceu, respectivamente, a recolonização por micro-organismos mesófilos e o surgimento de uma população termofílica na biomassa. Os resultados podem ter sido influenciados pela ausência da adição de dejetos líquidos nos respectivos períodos e também pela evaporação e precipitação do excedente de água dos dejetos adicionados anteriormente, juntamente com a intensa atividade metabólica microbiana, que proporcionou a liberação de água da biomassa devido à produção de calor. Adicionalmente, foi observada uma maior redução das partículas da biomassa, podendo ser atribuída às transformações físicas da mistura dos substratos pelos micro-organismos, no decorrer da COM passiva, concordando com Kunz et al. (2008) que avaliaram diferentes substratos para a compostagem de dejetos líquidos de suínos e verificaram que a serragem teve uma maior eficiência em evaporar água do que a maravalha. Os autores atribuíram à menor granulometria do substrato, que reduziu a perda de calor para o meio externo, fazendo com que fossem atingidas temperaturas maiores, o que proporcionou uma maior perda de umidade.

Com relação à matéria orgânica (MO total), a utilização da tecnologia COM passiva na degradação da mistura de dejetos líquidos de bovinos leiteiros e cama aviária promoveu, a partir do dia zero $(\mathrm{T} 1=85,0 \%)$, uma redução significativa dos seus teores. $\mathrm{O}$ mesmo aconteceu com o C orgânico total, enquanto que o conteúdo de cinzas aumentou significativamente durante o processo $(p<0,05)$, o que expressa uma maior concentração de componentes minerais, sendo resultado da mineralização da MO total por uma população microbiana heterogênea presente no decorrer do processo de compostagem, que depende tanto do conteúdo de $C$ como fonte de energia, quanto de $\mathrm{N}$ para a síntese de proteínas e reprodução (Fornes et al., 2012).

Entretanto, embora não se tenha constatado diferença significativa para o teor de $\mathrm{N}$ total e para a relação $\mathrm{C} / \mathrm{N}$ entre os períodos da COM passiva $(\mathrm{p}>0,05)$, pode ser verificado uma redução numérica da proporção entre C e N, quando comparado ao T1 (36/1), estando o valor dentro da faixa recomendada por Inácio e Miller (2009), que é de 30 a 40/1. A redução da relação $\mathrm{C} / \mathrm{N}$ ao longo da $\mathrm{COM}$ passiva reflete a proporção de MO total decomposta, bem como a sua estabilização durante o processo.

Em decorrência disso, reduções significativas de $\mathrm{pH}$ foram observadas entre os períodos iniciais T1 $(9,0)$, T2 $(8,5)$ e T3 $(7,7)$ (tabela II), possivelmente devido à liberação de ácidos orgânicos e $\mathrm{CO}_{2}$ pela atividade microbiana na degradação da $\mathrm{MO}$ total, favorecendo a diminuição do pH do meio (Liu et al., 2011).

Considerando a composição mineral da biomassa, verificou-se que o teor de P total aos 30 dias T4 (9,1 g $\left.\mathrm{kg}^{-1}\right)$ foi significativamente superior ao T1 $\left(6,0 \mathrm{~g} \mathrm{~kg}^{-1}\right)$, não diferindo dos outros períodos da $\mathrm{COM}$ passiva $(p>0,05)$. O aumento da concentração de $\mathrm{P}$ total pode ser resultado da atividade microbiana, que o utiliza para o crescimento e desenvolvimento celular (Kaosol et al., 2012). Resultados semelhantes foram encontrados para o teor de $\mathrm{Mg}$ total, que no mesmo período foi significativamente superior T4 $\left(7,2 \mathrm{~g} \mathrm{~kg}^{-1}\right)$ ao T1 $\left(5,1 \mathrm{~g} \mathrm{~kg}^{-1}\right)$. Inácio e Miller (2009) explicam que os nutrientes, que se tornam disponíveis com a mineralização da $\mathrm{MO}$ total, permanecem dentro da massa microbiana contida nos substratos compostados e nas substâncias húmicas. 
Tabela III. Composicão química da mistura de dejetos líquidos de bovinos leiteiros e cama aviária submetidos aos processos de COM (compostagem passiva + compostagem ativa) e C+VER (compostagem passiva + vermicompostagem) (Chemical composition of a mixture of liquid residues of dairy cattle and poultry litter subjected to COM (composting passive aeration + composting active aeration) na C + VER (composting passive aeration + vermicomposting)).

\begin{tabular}{|c|c|c|c|c|c|c|c|c|c|c|c|}
\hline & UMID & $\mathrm{CZ}$ & $\mathrm{N}$ & $\mathrm{MO}$ & $C$ & \multirow{2}{*}{$\mathrm{pH}$} & \multirow{2}{*}{$\mathrm{C} / \mathrm{N}$} & $\mathrm{P}$ & $\mathrm{K}$ & $\mathrm{Ca}$ & $\mathrm{Mg}$ \\
\hline & & & $\%$ & & & & & \multicolumn{4}{|c|}{$\mathrm{g} \mathrm{kg}^{-1}$} \\
\hline COM & $67,0^{\mathrm{B}}$ & $24,7^{\mathrm{B}}$ & $1,5^{\mathrm{B}}$ & $75,9^{A}$ & $42,2^{\mathrm{A}}$ & $8,7^{B}$ & $29,1^{\mathrm{A}}$ & 10,9 & $20,6^{A}$ & $29,9^{B}$ & 8,4 \\
\hline$C+$ VER & $70,5^{A}$ & $29,0^{\mathrm{A}}$ & $1,6^{A}$ & $71,0^{\mathrm{B}}$ & $39,4^{\mathrm{B}}$ & $9,0^{A}$ & $25,5^{\mathrm{B}}$ & 10,7 & $16,0^{B}$ & $37,9^{A}$ & 9,0 \\
\hline
\end{tabular}

Médias seguidas de letras maiúsculas diferentes, na coluna, diferem entre si por contrastes ortogonais $(p<0,05)$; UMID= umidade; $\mathrm{MO}=$ matéria orgânica total; $\mathrm{CZ}=$ cinzas; $\mathrm{N}=$ nitrogênio total; $\mathrm{C}=$ carbono orgânico total; $\mathrm{C} / \mathrm{N}=$ relação carbono/nitrogênio; $\mathrm{P}=$ fósforo total; $\mathrm{K}=$ potássio total; Ca= cálcio total; Mg= magnésio total.

De forma diferente, o K da mistura dos substratos iniciais T1 $\left(15,0 \mathrm{~g} \mathrm{~kg}^{-1}\right)$ diminuiu significativamente nos três períodos subsequentes, assumindo valores de 8,1 $\mathrm{g} \mathrm{kg}^{-1}$ (T2), 6,0 $\mathrm{g} \mathrm{kg}^{-1}$ (T3) e 8,9 $\mathrm{g} \mathrm{kg}^{-1}$ (T4), mantendo-se numericamente reduzido aos 40 dias T5 $\left(10,1 \mathrm{~g} \mathrm{~kg}^{-1}\right)$ da COM passiva. Kiehl (2004) atribui os resultados encontrados ao fenômeno de adsorção, que leva a formação de complexos insolúveis. O teor de Ca total da biomassa, no período T5 $\left(42,6 \mathrm{~g} \mathrm{~kg}^{-1}\right)$ da COM passiva aumentou significativamente em relação ao T1 $\left(19,5 \mathrm{~g} \mathrm{~kg}^{-1}\right)$. Os resultados sugerem que a liberação de Ca pode ter sido influenciada pelas concentrações de lignina e fenólicos solúveis (Kiehl, 1985).

$\mathrm{O}$ uso do método COM ativa promoveu decréscimos significativos nos teores de MO total $(78,4 \%)$ e C orgânico total $(43,5 \%$ ) entre a fase inicial (T6) e a fase final (T8) do processo $(p<0,05)$, podendo-se verificar os respectivos valores de $73,6 \%$ e $40,9 \%$. Conforme esperado, foi constatado aumento significativo no teor de cinzas nos mesmos períodos, concordando com Raupp e Oltamanns (2005) que afirmam que o teor de cinzas tende a apresentar-se mais elevado no composto maduro devido à mineralização da $\mathrm{MO}$ total elevar o teor de minerais.

Entretanto, na tabela II, não foi verificada diferença significativa para os teores de $\mathrm{P}, \mathrm{Ca}$ e $\mathrm{Mg}$ totais entre os períodos no decorrer do processo $(p>0,05)$. Porém, o teor de K diminuiu significativamente entre os períodos T7 $\left(25,2 \mathrm{~g} \mathrm{~kg}^{-1}\right)$ e T8 $\left(19,5 \mathrm{~g} \mathrm{~kg}^{-1}\right)(\mathrm{p}<0,05)$. Os resultados sugerem que quantidades de $\mathrm{K}$ no chorume produzido, devido a adição de dejetos líquidos, podem ter percolado da pilha.

Considerando a relação $\mathrm{C} / \mathrm{N}$ da biomassa, podem ser observadas reduções significativas entre os dois períodos iniciais $(31,8 / 1$ e 30,8/1) e a fase final $(24,7 / 1)$ da COM ativa $(p<0,05)$. Diferentemente, o teor de $\mathrm{N}$ total da biomassa, na fase final do processo $(1,7 \%)$, foi significativamente superior ao dos períodos iniciais $(1,4 \%, 1,4 \%)$, em consequência da disponibilidade de C orgânico para ser utilizado como fonte de energia pelos micro-organismos, o que permitiu a assimilação do N pela biomassa microbiana (Inácio e Miller, 2009). Os fatos sugerem que os dejetos líquidos adicionados à biomassa serviram de fonte de $\mathrm{C}$ orgânico para os micro-organismos, já que a cama aviária apresentava baixa relação $C / N$ inicial $(20,9 / 1)$, concordando com Liang et al. (2006) que afirmam que o emprego de substratos ricos em C disponível reduz as perdas de
N durante a compostagem de resíduos orgânicos com alta concentração de $\mathrm{N}$ total.

Desta forma, pode-se constatar que o $\mathrm{pH}$ do T8 $(9,0)$ foi significativamente superior aos períodos iniciais do processo da COM ativa $(\mathrm{p}<0,05)$, possivelmente devido à formação de grupos fenólicos durante o processo de biotransformação da lignina (Bernal et al., 2009), componente da maravalha da cama aviária. Lhadi et al. (2006) acrescentam que no decorrer do processo de compostagem, a degradação de componentes facilmente degradáveis conduz ao aumento da fração ligno-húmica recalcitrante.

No decorrer da vermicompostagem da mistura de dejetos líquidos de bovinos leiteiros e cama aviária (tabela II) pode ser observado, a partir do T9 $(77,5 \%)$, uma redução significativa dos teores de MO total nos períodos subsequentes, sendo constatados valores de $66,5 \%$ (T10) e $69,3 \%$ (T11). Conforme esperado, o teor de cinzas dos dois últimos períodos, T10 (33,5\%) e T11 $(30,7 \%)$, foram significativamente superiores ao T9 $(22,5 \%)$. De outra forma, foram encontrados decréscimos significativos nos teores de $C$ orgânico total nos mesmos períodos, que assumiram valores de $36,9 \%$ (T10) e 38,5\% (T11). Diferentemente, pode ser observado um aumento significativo do teor de $\mathrm{N}$ total $(1,9 \%)$ aos 60 dias (T11) de vermicompostagem $(p<0,05)$. Assim, as reduções de $C$ orgânico total e os acréscimos de $\mathrm{N}$ total nos dois últimos períodos contribuíram para a redução significativa da relação $\mathrm{C} / \mathrm{N}$ observada aos 60 dias $(20,4 / 1)$. A fragmentação e a digestão parcial da mistura dos substratos pelas minhocas, conjuntamente com sua microflora intestinal e também a ação conjunta dos micro-organismos mesófilos da biomassa, promoveram a mineralização da $\mathrm{MO}$ total, o que conduziu a perdas de $\mathrm{C}$ orgânico total e acréscimos no conteúdo de $\mathrm{N}$ total, estando diretamente relacionados à densidade de minhocas no substrato (Aira et al., 2008). Xing et al. (2012) utilizando a Eisenia fetida (Savigny, 1826) na vermicompostagem da mistura de cinco tipos de lodo de esgoto com esterco bovino, observaram que o $\mathrm{C}$ orgânico dissolvido e a relação $\mathrm{C} / \mathrm{N}$ dos substratos diminuíram significativamente após o processo.

A redução significativa do teor de umidade nos períodos finais da vermicompostagem, T10 (68,1\%) e T11 $(66,0 \%)$, não prejudicaram a atividade das minhocas na degradação da $\mathrm{MO}$ total. Os resultados discordam de Garcia e Zidko (2006) que afirmam que a espécie Eisenia fetida (Savigny, 1826) sobrevive melhor em subs- 
tratos com 70 a $85 \%$ de umidade, pois elas respiram e excretam substâncias através da pele.

Considerando o $\mathrm{pH}$ da massa em vermicompostagem, pode ser verificado que não houve diferença significativa no decorrer do processo $(p>0,05)$, sendo observado que os valores situaram-se dentro da faixa alcalina $(8,7-9,1)$. Na tabela II, verifica-se que a manutenção do $\mathrm{pH}$ alcalino pode ter ocorrido devido a atividade das glândulas calcíferas, que absorveram o excesso de Ca $\left(36,5 \mathrm{~g} \mathrm{~kg}^{-1}\right)$. As glândulas calcíferas possuem a enzima anidrase carbônica, que catalisa a fixação do $\mathrm{CO}_{2}$ em $\mathrm{CaCO}_{3}$, prevenindo assim naturalmente a queda do pH (Padmavathiamma et al., 2008).

No que diz respeito ao conteúdo de minerais da biomassa, verificou-se um aumento significativo do teor de $\mathrm{P}$ total $\left(14,8 \mathrm{~g} \mathrm{~kg}^{-1}\right)$ e de $\mathrm{K}\left(19,4 \mathrm{~g} \mathrm{~kg}^{-1}\right)$ no período final da vermicompostagem $(\mathrm{p}<0,05)$. Tripathi e Bhardway (2004) salientam que a mineralização e a mobilização pelas bactérias, bem como a ação da fosfatase no intestino das minhocas pode ser a principal razão para o aumento do $\mathrm{P}$ no vermicomposto.

Na tabela III, pode ser observado que a combinação entre COM Passiva + VER (C + VER) proporcionou uma redução significativa dos teores de $\mathrm{MO}$ total (71\%) e de C orgânico total $(39,4 \%)$ e, consequentemente, uma elevação significativa do conteúdo de cinzas $(p<0,05)$. Da mesma forma, o teor de $\mathrm{N}$ total $(1,6 \%)$ foi significativamente superior ao da biomassa tratada pelo método combinado de COM (Ativa + Passiva). Em decorrência disso, verificou-se um decréscimo significativo da relação C/N (25,5/1) dos substratos vermicompostados. Os resultados encontrados concordam com Fornes et al. (2012) que afirmam que na vermicompostagem ocorre uma maior liberação de $\mathrm{CO}_{2}$ do que na compostagem, devido à atuação das minhocas e dos micro-organismos na mineralização da $\mathrm{MO}$ total, que promovem o declínio do C orgânico total. Os micro-organismos produzem enzimas extracelulares, que degradam a celulose e compostos fenólicos distintos, aumentando assim a degradação do material ingerido, enquanto que as minhocas digerem cadeias longas de polissacarídeos e aumentam a colonização microbiana, que promove a aceleração da degradação da matéria orgânica e a fixação do $\mathrm{N}$, contribuindo para um maior declínio da relação C/N (Aira et al., 2008). Dominguez et al. (2009) afirmam que certa quantidade de $\mathrm{N}$ também é adicionada pelas minhocas na forma de muco, hormô- nio, enzimas e substâncias nitrogenadas excretadas, colaborando para diminuir a relação $\mathrm{C} / \mathrm{N}$.

O teor de $\mathrm{pH}(9,0)$ dos substratos tratados com $\mathrm{C}+$ VER foi significativamente superior ao da biomassa COM T6 $(8,7)(p<0,05)$, demonstrando novamente a influência das glândulas calcíferas, que absorveram o excesso de $\mathrm{Ca}\left(36,8 \mathrm{~g} \mathrm{~kg}^{-1}\right)$ da cama aviária. Os resultados concordam com Lim et al. (2012) que utilizando a espécie E. eugeniae na degradação de diferentes proporções da mistura de casca de arroz e resíduos de frutas verificaram que o $\mathrm{pH}$ manteve-se alcalino em todos os tratamentos.

Considerando o conteúdo mineral, pode-se constatar na tabela III, que não houve diferença significativa entre a $\mathrm{C}+\mathrm{VER}$ e a COM, para os teores de P total e $\mathrm{Mg}$ total ( $p>0,05)$. Entretanto, o teor de $\mathrm{K}$ da mistura dos resíduos orgânicos submetidos a COM (20,6 $\left.\mathrm{g} \mathrm{kg}^{-1}\right)$ foi significativamente superior aos tratados pela $\mathrm{C}+\mathrm{VER}$ $\left(16,0 \mathrm{~g} \mathrm{~kg}^{-1}\right)(\mathrm{p}<0,05)$, sugerindo que o aumento significativo do teor de umidade $(70,5 \%)$ do vermicomposto pode ter influenciado o declínio da concentração desse mineral. Conforme esperado, houve um aumento significativo no teor de Ca total $\left(37,9 \mathrm{~g} \mathrm{~kg}^{-1}\right)$ da mistura dos substratos sujeitos a C + VER, possivelmente devido à utilização de $\mathrm{CaSO}_{4}$ para a desinfecção da cama aviária. Matos (2014) explica que o íon cálcio se dissocia do ânion sulfato, formando carbonato de cálcio, o que acaba contribuindo para o pH alcalino (tabela III).

Na tabela IV, pode ser observado a composição química do composto e do vermicomposto ao final de 100 dias da COM e da C + VER, respectivamente, em que o vermicomposto foi significativamente superior ao composto. A redução significativa dos teores de $\mathrm{MO}$ total $(69,2 \%)$, de C orgânico total $(38,4 \%)$ e da relação C/N (20,5/1), bem como o aumento significativo nos conteúdos de cinzas $(30,8 \%), \mathrm{N}$ total $(1,9 \%), \mathrm{P}(15 \mathrm{~g}$ $\left.\mathrm{kg}^{-1}\right)$ e $\mathrm{Mg}$ totais $\left(9,8 \mathrm{~g} \mathrm{~kg}^{-1}\right)$ confirmam o resultado $(\mathrm{p}<0,05)$. Da mesma forma, Cotta et al. (2015) compararam a compostagem e a vermicompostagem de resíduos vegetais, esterco bovino e serragem e verificaram que os vermicompostos de todos os tratamentos apresentaram um decréscimo maior da relação $\mathrm{C} / \mathrm{N}$ e maiores teores de nutrientes minerais, atribuindo a mineralização da matéria orgânica pelos micro-organismos e pelas minhocas. Os valores encontrados para a composição química do vermicomposto estão dentro do recomendado pela $I_{N}{ }^{\circ} 25 / 2009$ (Brasil, 2009), com exceção do teor de umidade que foi de 66,1\%. Porém,

Tabela IV. Composição química do composto e do vermicomposto obtidos ao final de 100 dias da COM (compostagem passiva + compostagem ativa) e da C +VER (compostagem passiva + vermicompostagem) (Chemical composition of composting and vermicomposting obtained at the end of 100 days of COM (composting passive aeration + composting active aeration) and C + VER (composting passive + vermicomposting)).

\begin{tabular}{|c|c|c|c|c|c|c|c|c|c|c|c|}
\hline \multirow{2}{*}{ Produtos finais } & UMID & $\mathrm{CZ}$ & $\mathrm{N}$ & MO & $\mathrm{C}$ & \multirow{2}{*}{$\mathrm{pH}$} & \multirow{2}{*}{$\mathrm{C} / \mathrm{N}$} & $P$ & $\mathrm{~K}$ & $\mathrm{Ca}$ & $\mathrm{Mg}$ \\
\hline & & & $\%$ & & & & & \multicolumn{4}{|c|}{$\mathrm{g} \mathrm{kg}^{-1}$} \\
\hline Composto & $63,1^{\mathrm{B}}$ & $26,4^{\mathrm{B}}$ & $1,7^{\mathrm{B}}$ & $73,6^{A}$ & $41,0^{A}$ & 9,0 & $24,7^{\mathrm{A}}$ & $11,1^{\mathrm{B}}$ & 19,5 & 30,1 & $8,3^{\mathrm{B}}$ \\
\hline Vermicomposto & $66,1^{\mathrm{A}}$ & $30,8^{A}$ & $1,9^{A}$ & $69,2^{\mathrm{B}}$ & $38,4^{\mathrm{B}}$ & 9,1 & $20,5^{\mathrm{B}}$ & $15,0^{\mathrm{A}}$ & 19,6 & 36,3 & $9,8^{A}$ \\
\hline IN-25 & $\leq 50 \%$ & - & $\geq 0,5 \%$ & $\geq 40 \%$ & $\geq 15 \%$ & $\geq 6,0$ & $\leq 20$ & $\mathrm{~cd}$ & $\mathrm{~cd}$ & $\geq 1 \%$ & $\geq 1 \%$ \\
\hline
\end{tabular}

Médias seguidas de letras maiúsculas diferentes, na coluna, diferem entre si por contrastes ortogonais ( $p<0,05)$; UMID= umidade; $M O=$ matéria orgânica total; $\mathrm{CZ}=$ cinzas; $\mathrm{N}=$ nitrogênio total; $\mathrm{C}=$ carbono orgânico total; $\mathrm{C} / \mathrm{N}=$ relação carbono/nitrogênio; $\mathrm{P}=$ fósforo total; $\mathrm{K}=$ potássio total; $\mathrm{Ca}=$ cálcio total; $\mathrm{Mg}=$ magnésio total; cd= conforme declarado. Instrução Normativa n²5/2009 (Brasil, 2009). 
Guo et al. (2012) constataram, através de teste de germinação, que o conteúdo de umidade teve um efeito insignificante na qualidade do composto.

A relação C/N de 24,7/1 do composto poderia causar deficiência temporária de $\mathrm{N}$ às plantas, devido ao consumo de $\mathrm{N}$ do solo pelos micro-organismos (Kiehl, 2004). Valente et al. (2013) ressaltam que além da relação $\mathrm{C} / \mathrm{N}$, outros parâmetros de avaliação da qualidade do adubo orgânico devem ser levados em consideração pela Instrução Normativa n ${ }^{\circ}$ 25/2009 (BRASIL, 2009), para que o produto seja considerado humificado e/ou maturado. Diversos estudos abordam outros métodos para avaliar o grau de maturidade do produto final, como o índice de germinação (Komilis e Tziouvaras, 2009), a respirometria (Ponsá et al., 2009), o teor de substâncias húmicas (Castaldi et al., 2005) e a atividade enzimática da desidrogenase e da lipase (Ruggieri et al., 2008).

\section{CONCLUSÕES}

A compostagem pelo método aeração passiva não é eficiente na estabilização da mistura de dejetos líquidos de bovinos leiteiros e cama aviária em um tempo de 40 dias de processo.

A utilização da compostagem pelo método aeração ativa necessita de um tempo maior que 60 dias para promover a estabilização da mistura dos substratos.

O processo de vermicompostagem é uma tecnologia eficiente no tratamento da mistura de dejetos líquidos de bovinos leiteiros e cama aviária, promovendo a bioestabilização dos substratos em um período de 60 dias.

\section{BIBLIOGRAFIA}

Aira, M.; Sampedro, L.;Monroy, F. and Domínguez, J. 2008. Detritivorous earthworms directly modify the structure, thus altering the functioning of a microdecomposer food web. Soil Biol Biochem, 40: 251 1-2516.

Barrington, S.; Choinére, D.; Trigui, M.and Knight, W. 2003. Compost convective airflow under passive aeration. Bioresource Technol, 86: 259-266.

Bernal, M.P.; Alburquerque, J.A. and Moral, R. 2009. Composting of animal manures and chemical criteria for compost maturity assessment. A review. Bioresource Technol, 100: 5444-5453.

BRASIL. Ministério da Agricultura, Pecuária e Abastecimento. Instrução Normativa $\mathrm{n}^{\circ} 25$, de 23 de julho de 2009. Dispõe sobre as especificações e as garantias, as tolerâncias, o registro, a embalagem e a rotulagem dos fertilizantes orgânicos simples, mistos, compostos, organominerais e biofertilizantes destinados à agricultura. www. agricultura.gov.br (04/02/2011).

Castaldi, P.; Alberti, G.; Merella, R. and Melis, P. 2005. Study of the organic matter evolution during municipal solid waste composting aimed at identifying suitable parameters for the evaluation of compost maturity. Waste Manage, 25: 209-213.

Cooper, M.; Zanon, A.R.; Reia, M.Y. eMorato, R.W. 2010. Compostagem e reaproveitamento de resíduos orgânicos agroindustriais: teórico e prático. ESALQ. Piracicaba. 35 pp.

Cotta, J.A. de O.; Carvalho, N.L.C.; Brum, T. da S. e Rezende, M.O de O. 2015. Compostagem versus vermicompostagem: comparação das técnicas utilizando resíduos vegetais, esterco bovino e serragem. Eng Sanit Ambient, 20: 65-78.

Dai Prá, M.A. 2006. Desenvolvimento de um sistema de compostagem para o tratamento de dejetos de suínos. Dissertação (Mestrado em
Zootecnia). Faculdade de Agronomia Eliseu Maciel. Universidade Federal de Pelotas. Pelotas. RS. 127 pp.

Domínguez, J.; Aira, M. and Gómez-Brandón, M. 2009. El papel de las lombrices de tierra en la descomposición de la materia orgánica y el ciclo de nutrientes. Ecosistemas, 18: 20-31.

Fornes, F.; Mendoza Hernández, D.; García de la Fuente, R.; Abad, M. and Belda, R.M. 2012. Composting versus vermicomposting: a comparative study of organic matter evolution through straight and combined processes. Bioresource Technol, 118: 296-305.

Garcia, F.R.M. e Zidko, A. 2006. Criação de minhocas: As operárias do húmus. Editora Ríegel. Porto Alegre. 112 pp.

Guo, R.; Li, G.; Jiang, T.; Schuchardt, F.; Chen, T.; Zhao, Y. and Shen, Y. 2012. Effect of aeration rate, $\mathrm{C} / \mathrm{N}$ ratio and moisture content on the stability and maturity of compost. Bioresource Technol, 112: 171-178.

Inácio, C. de T. e Miller, P.R.M. 2009. Compostagem: Ciência e prática para a gestão de resíduos orgânicos. Embrapa Solos. Rio de Janeiro. $144 \mathrm{pp}$.

Kader, N.A.E.; Robin, P.; Paillat, J.M. and Leterme, P. 2007. Turning, compacting and the addition of water as factors affecting gaseous emissions in farm manure composting. Bioresource Technol, 98: 2619-2628.

Kaosol, T.; Kiepukdee, S. and Towatana, P. 2012. Influence of nitrogen containing wastes addition on natural aerobic composting of rice straw. American J Agric Biol Sci, 7: 121-128.

Kiehl, E.J. 1985. Fertilizantes orgânicos. Editora Agronômica Ceres Ltda. Piracicaba. 492 pp.

Kiehl, E.J. 2004. Manual de compostagem: maturação e qualidade do composto. E.J. Kiehl. Piracicaba. 173 pp.

Komilis, D.P. and Tziouvaras, I.S. 2009. A statistical analysis to assess the maturity and stability of six composts. Waste Manage, 29: 1504-1513.

Kunz, A.; Bortoli, M. e Higarashi, M.M. 2008. Avaliação do manejo de diferentes substratos para compostagem de dejetos líquidos de suínos. Acta Ambiental Catarinense, 5: 7-19.

Lhadi, E.K.; Tazi, H.; Aylaj, M.; Genenini, P.L. and Adani, F. 2006. Organic matter evolution during co-composting of the organic fraction of municipal waste and poultry manure. Bioresource Technol, 97 : $2117-2123$

Liang, Y.; Leonard, J.J.; Fedds, J.J.R. and McGill, W.B. 2006. Influence of carbon and buffer amendment on ammonia volatilization in composting. Bioresource Technol, 97: 748-761.

Lim, S.L.; Wu, T.Y.; Sim, E.Y.S.; Lim, P.N. and Clarke, C. 2012. Biotransformation of rice husk into organic fertilizer through vermicomposting. Ecol Eng, 41: 60-64.

Liu, D.; Zhang, R.; Wu, H.; Xu, D.; Tang, Z.; Yu, G.; Xu, Z. and Shen, Q. 2011. Changes in biochemical and microbiological parameters during the period of rapid composting of dairy manure with rice chaff. Bioresource Technol, 102: 9040-9049.

Matos, A.T. de. 2014. Tratamento e aproveitamento agrícola de resíduos sólidos. Editora Universidade Federal de Viçosa. Viçosa. 236 pp.

Ndegwa, P.M. and Thompson, S.A. 2001. Integrating composting and vermicomposting in the treatment and bioconversion of biosolids. Bioresource Technol, 76: 107-112.

Padmavathiamma, P.K.; Li, L.Y. and Kumari, U.R. 2008. An experimental study of vermin-biowaste composting for agricultural soil improvement. Bioresource Technol, 99: 1672-1681.

Ponsá, S.; Pagans, E. and Sánchez, A. 2009. Composting of dewatered wastewater sludge with various ratios of pruning waste used as a bulking agent and monitored by respirometer. Biosystems Engineering, 102: 433-443.

Raupp, J. and Oltamanns, M. 2005. Nutrient turnover and losses during composting of farmyard manure - results of outdoor experiment over 11 years. In: Conference Researching Sustainable Systems. Proceedings... ISOFAR. Adelaide, Alemanha. pp. 231-234.

Ruggieri, L.; Artola, A.; Gea, T. y Sáchez, A. 2008. Biodegradation of animal fats in a co-composting process with wastewater sludge. Int Biodeter Biodegr, 62: 297-303

SAS Institute Inc. 2002-2003. Statistical analysis system. Release 9.1. (Software). SAS Institute Inc. Cary. USA. 
Silva, D.J. e Queiroz, A.C. de. 2004. Análise de alimentos: Métodos químicos ebiológicos. Universidade Federal de Viçosa. Viçosa. 235 pp.

Tedesco, M.J.; Gianello, C.; Bissani, C.A.; Bohnen, H. e Volkwweiss, S.J. 1995. Análises de solo, plantas e outros materiais. POA: Faculdade de Agronomia/UFRGS. 174 pp.

Tripathi, G. and Bhardwaj, P. 2004. Comparative studies on biomass production, life cycles and composting efficiency of Eisenia fetida (Savigny) and Lampito mauritii (Kinberg). Bioresource Technol, 92: 275-283.

Valente, B.S.; Xavier, E.G.; Moraes, P. de O.; Manzke, N.E. e Roll, V.F.B. 2011. Eficiência do SISCODE e da aeração passiva no tratamento de resíduos da produção animal no município de Capão do Leão/ RS. Rev Eng Sanit Amb, 16: 231-236.

Valente, B.S.; Xavier, E.G.; Manzke, N.E.; Almeida, G.R. de. e Roll, V.F.B. 2013. Composição físico-química de vermicompostos comercializa- dos na região do município de Pelotas/RS. Rev Var Sci Agrárias, 3: 119-132.

Vig, A.P.; Singh, J.; Wani, S.H. and Dhaliwal, S.S. 2011 . Vermicomposting of tannery sludge mixed with cattle dung into valuable manure using earthworm Eisenia foetida (Savigny). Bioresource Technol, 102: 7941-7945.

Yadav, K.D.; Tare, V. and Ahammed, M.M. 2012. Integrated compostingvermicomposting process for stabilization of human faecal slurry. Ecol Eng, 47: 24-29

Xing, M.; Li, X.; Yang, J.; Huang, Z. and Lu, Y. 2102. Changes in the chemical characteristics of water-extracted organic matter from vermicomposting of sewage sludge and cow dung. J Hazard Mater, 205: 24-31 
